Running Head: CLOSENESS AND MORALITY PREDICT BEING MOVED

Interpersonal closeness and morality predict feelings of being moved

\author{
Beate Seibt \\ University of Oslo \\ and Instituto Universitário de Lisboa (ISCTE-IUL), Lisboa, Portugal
}

Thomas W. Schubert

Janis H. Zickfeld

University of Oslo

Alan Page Fiske
University of California, Los Angeles

In press at Emotion. (C) 2016 American Psychological Association. This paper is not the copy of record and may not exactly replicate the authoritative document published in the APA journal. Please do not copy or cite without authors permission. The final article will be available, upon publication, at: $10.1037 /$ emo0000271

\footnotetext{
Author Note

Beate Seibt, Department of Psychology, University of Oslo, Norway and Centro de Investigação e Intervenção Social (CIS-IUL), Instituto Universitário de Lisboa (ISCTE-IUL), Portugal; Thomas W. Schubert and Janis H. Zickfeld, Department of Psychology, University of Oslo, Norway; Alan Page Fiske, Department of Anthropology, University of California, Los Angeles. We thank the Kama muta lab for helpful feedback and discussions.

Correspondence concerning this article should be addressed to Beate Seibt, Postboks 1094 Blindern, 0317 Oslo, Norway. E-mail: beate.seibt@psykologi.uio.no.
} 


\begin{abstract}
The emotion commonly labelled in English being moved or touched is widely experienced but only tacitly defined, and has received little systematic attention. Based on a review of conceptualizations from various disciplines, we hypothesize that events appraised as an increase in interpersonal closeness, or as moral acts, when sufficiently intense, elicit a positive emotion typically labeled 'being moved', and characterized by tears, goosebumps, and a feeling of warmth in the chest. We predicted this to be true for events a person participates in, as well as for events they observe. In Study 1, we elicited reports of recent episodes of weeping evoked by something positive, and also weeping because of something negative; we measured emotion terms, bodily sensations, and appraisals in a US sample. We discovered that events of positive tears, rather than negative tears, were associated with self-reported being moved or touched, with goosebumps, with feelings of chest warmth, and with the appraisals of increased closeness and moral acts. These appraisals mediated the difference in being moved between positive and negative events. We further found that appraisal patterns for personally experienced events were similar to the patterns for observed events. Finally, the two appraisals were more closely associated with being moved than with other emotion labels. This was corroborated in Study 2 in the US and Norway, where we induced being moved, sadness, anxiety, and happiness through videos and measured these emotions, plus the appraisals and sensations from Study 1.
\end{abstract}

Words: $241 / 250$

Keywords: appraisal; tears; emotion; goosebumps; being moved 


\section{Interpersonal closeness and morality predict feelings of being moved}

In "The expression of emotion in man and animals", Charles Darwin remarked: "The feelings which are called tender ... are remarkable ... from so readily exciting the secretion of tears. Many a father and son have wept on meeting after a long separation, especially if the meeting has been unexpected" (1890, p. 216-217). William James wrote: "In listening to poetry, drama, or heroic narrative we are often surprised at the cutaneous shiver which like a sudden wave flows over us, and at the heart-swelling and the lachrymal effusion [tears] that unexpectedly catch us at intervals" (1890, p. 457).

These accounts have in common that they talk about tears shed because of something positive, rather than tears of sadness, anger or frustration. More recent authors have echoed these ideas and called the feeling state being moved or sentimentality. Many of the suggested appraisals for being moved have a common theme of increased interpersonal closeness. These include solidarity, a communion of souls, or reconciliation (Claparède, 1930), love/acceptance (Panksepp, 1995), attachment concerns (Frijda, 1988), reunification (Tan \& Frijda, 1999), love and forgiveness (Konečni, 2005), fulfilment of the phantasy of union (Neale, 1986), and reconciliatory moments (Menninghaus, Wagner, Hanich, \& Wassiliwizky, 2015).

Other suggested elicitors of being moved can be summarized under the theme of moral acts: generous acts (Claparède, 1930), sacrifice and generosity (Konečni, 2005), prosocial acts (Hanich, Wagner, Shah, Jacobsen, \& Menninghaus, 2014), and the emergence of positive core values held by a moral community from negative values (Cova \& Deonna, 2014). Haidt and colleagues (Algoe \& Haidt, 2009; Haidt, 2003) proposed that observing acts of purity, virtue or moral beauty causes the emotion elevation, which they note is often called being touched, moved, or inspired. 
About half the authors analyzing being moved or positive tears only write about this as an emotion in response to art or narratives, or witnessing others' actions (Algoe \& Haidt, 2009; Frijda, 1988; James, 1890; Neale, 1986; Panksepp, 1995). The other half see this as an emotional response also to events in which the person herself directly engages or participates (Claparède, 1930; Cova \& Deonna, 2014; Darwin, 1890; Hanich et al., 2014; Tan \& Frijda, 1999). Thus, it is unclear at current whether the same or different appraisals underlie these two cases.

Regarding the sensations, there is a consensus that people who are moved have moist eyes, cry or weep, and feel choked up (Cova \& Deonna, 2014; Miceli \& Castelfranchi, 2003; Scherer \& Zentner, 2001; Vingerhoets \& Bylsma, 2015; Vingerhoets, 2013). In addition, being moved is thought to involve chills or goosebumps (Konečni, 2005; Wassiliwizky, Wagner, \& Jacobsen, 2015), which indeed have been measured with a camera (Benedek \& Kaernbach, 2011). The third frequently mentioned symptom of being moved is a sense of warmth in the center of the chest (Cova \& Deonna, 2014; Frijda, 1988; Schnall, Roper, \& Fessler, 2010; Tan \& Frijda, 1999; Tan, 2009).

In sum, scholars from different disciplines have suggested that certain positive events evoke tears. There is no consensus about which events do so, but two themes emerge from these literatures: increased interpersonal closeness and moral acts. Surprisingly little empirical research has been conducted on these ideas. In particular, none of the authors discussed how their assumed elicitors could be operationalized, and no published studies have tested any theory of the elicitors of being moved. Furthermore, it is unclear whether the same appraisals lead to positive tears for events in which a person is directly involved, or only those that the person observes. Finally, there is a consensual claim, but hardly any data, on the subjective experience and bodily sensations that go along with experiences of being moved. 
Our first study collected episodes of tears shed because of something positive from US participants. To obtain discriminant validity, we also collected episodes of tears resulting from something negative. We predicted that events leading to positive tears compared to negative tears (1) evoke an emotion people call "moved" or "touched", (2) also evoke goosebumps and the perception of chest warmth, and (3) are appraised as involving an increase in interpersonal closeness and a moral act (our two focal appraisals) ${ }^{1}$. This prediction was based on prior conceptualizations as well as on our own qualitative research (Fiske, Schubert \& Seibt, 2017). We also predicted (4) that the two appraisals mediate the difference in being moved across events, and (5) that they predict being moved both for episodes which participants observed and episodes in which they were actively involved. (6) Finally, we expected that being moved is a distinct emotion and therefore would be related to the two appraisals beyond its common variance with other emotion terms such as admiration or awe. To corroborate hypothesis 6 we conducted a second study, this time with video stimuli that each induced one of four emotions: happiness, sadness, anxiety, or being moved. We now sampled from two cultures, Norway and the US, to broaden the generalizability of the findings. Norway has the lowest and the US the highest heterogeneity of long-history migration (1 versus 83 source countries, Putterman \& Weil, 2010, scored following Rychlowska et al., 2015). Norway also scores lower on individualism than the US (69 vs. 91, Hofstede, 2001, p. 215) and higher on ingroup collectivism practices (GLOBE index 5.34 vs. 4.25, House, Hanges, Javidan, \& Dorfman, 2004). These factors are important for norms guiding emotional expressivity (Rychlowska et al., 2015).

\footnotetext{
${ }^{1}$ Three further appraisals were assessed for exploratory reasons (see Supplement).
} 
The Internal Review Board of the Department of Psychology, University of Oslo approved the studies. We will publish all materials and quantitative data on osf.io, and provide the event descriptions on request.

\section{Study 1}

\section{Method}

Design. After providing informed consent participants described an episode in which they "got moist eyes or even shed a tear because of a positive [negative] feeling," Participants were instructed to write a short description (at least 300 characters) about a recent experience from the last three months, or else an earlier situation if they could not think of a recent episode. They then completed our measures. This sequence was repeated with the remaining instruction. Condition order was counterbalanced.

Participants. We retained 132 complete datasets from US Americans participating on Amazon MTurk (62 women), aged 19 to 69 years $(M=35.20, S D=11.32)$.

Measures. First, participants characterized the emotions they experienced during the episode on scales ranging from 1 (not at all) to 7 (extremely). Then they reported appraisals, sensations and finally demographic information. The Supplement contains details on methods and analyses.

\section{Results}

Being moved index. First, we tested whether participants characterized their emotion more often as moved or touched in the positive than in the negative tear condition. In a repeatedmeasures ANOVA we compared the average of moved and touched for negative and positive tears. Supporting hypothesis 1, intensity of being moved differed for condition, 
$F(1,131)=136.68, p<.001, \eta_{\mathrm{p}}{ }^{2}=.51$, with ratings being higher in the positive tears condition (Table 1).

Sensations. A 3 (sensation: weeping score vs. warm chest vs. chills/goosebumps) by 2 (condition: positive vs. negative) repeated ANOVA revealed a significant main effect of condition, $F(1,128)=22.44, p<.001, \eta_{\mathrm{p}}^{2}=.15$, with higher means in the positive condition, a main effect of sensation, $F(2,256)=74.13, p<.001, \eta_{\mathrm{p}}{ }^{2}=.37$, with highest means for weeping, followed by warm chest and chills/goosebumps, and an interaction, $F(2,256)=30.03, p<.001, \eta_{\mathrm{p}}^{2}=.19$. Supporting hypothesis 2 , ratings of warm chest and chills/goosebumps were higher for the episodes involving positive tears. Ratings for tears were higher for the episodes involving negative tears (Table 1).

Appraisals. We compared ratings on closeness and morality between conditions in a $2 \times 2$ repeated ANOVA. In line with hypothesis 3, both ratings were higher for positive than negative tears episodes, $F(1,130)=99.44, p<.001, \eta_{\mathrm{p}}{ }^{2}=.43$. Their mean levels also differed, $F(1,130)=11.19, p=.001, \eta_{\mathrm{p}}^{2}=.08$, with closeness having the highest ratings. There was no interaction effect for type of appraisal with condition, $F(1,130)=.08, p=.78, \eta_{\mathrm{p}}{ }^{2}=.001$ (Table 1 ).

Appraisals and Being Moved. Given that positive and negative tear episodes were appraised in different ways, we examined whether the two appraisals could explain why the positive tear episodes made participants more moved than the negative tear episodes. We tested whether the effect of condition (IV) on the being moved index (DV) was mediated by the appraisals of closeness and morality concurrently (MEMORE, Montoya \& Hayes, 2016). The model indicated indirect effects of condition on being moved via both the closeness appraisal, $B=.52,95 \% \mathrm{CI}[.22 ; .91]$ and the morality appraisal, $B=.49[.14 ; .82]$, the total effect being 1.00 $[.67 ; .1 .40]$, supporting hypothesis 4 . 
Prediction of being moved across perspectives. To test whether these appraisals predict being moved for episodes which participants observed and for episodes where they were actively involved, two assistants coded the episodes for perspective (see Supplement). In an ANCOVA, we predicted being moved for positive tears by perspective (participating vs. witnessing), closeness, morality, and their interactions with perspective. Supporting hypothesis 5, no significant interaction emerged, $F_{\mathrm{s}}(1,125)<1.6, p \mathrm{~s}>.21$. Only the main effect of closeness was significant, $F(1,125)=29.71, p<.001, \eta_{\mathrm{p}}{ }^{2}=.19$. We therefore dropped perspective and its interactions from the equation and obtained an overall effect of closeness of $B=.50$ [.32;.67], $t(128)=5.65, p<.001$. When used as the sole predictor, being moved was also predicted by morality, $B=.17[.02 ; .32], t(130)=3.22, p=.028$.

Other emotions. Does being moved relate to the appraisals over and above other emotions? As another test of discriminant validity, we entered the emotion ratings of happiness, sadness, awe, admiration, anger, anxiety and pride, along with the moved index, as predictors of the two appraisals in two MIXED models. Note that we reversed the regression direction.

Closeness was only related to being moved, $B=.36[.21 ; .51], t(249)=4.68, p<.001$. Morality was significantly related to both being moved, $B=.27[.12 ; .41], t(244)=3.64, p<.001$, and admiration, $B=.29[.16 ; .43], t(245)=4.11, p<.001$ (see Supplement). The significant regression weights for being moved support hypothesis 6.

\section{Study 2}

\section{Method}

Design. After providing informed consent, participants watched four videos in random order, each followed by the same set of questions. 
Participants. We retained 758 video impressions by 220 online participants (139 women; 108 Norwegian psychology undergraduates, 112 US Amazon MTurk workers) aged 19 to 69 years $(M=31.71, S D=12.39)$.

Materials. Four videos were selected to evoke being moved, happiness, sadness, and anxiety. After each video, participants were asked how moved, touched, happy, sad, or anxious the short clip made them feel (1 not at all to 7 extremely). Then they rated the same five appraisals as in Study 1, this time from 1 (not at all) to 5 (to a high degree). Sensations were assessed with items on 'Tears/Moist eyes' (weeping), 'Warm Chest', and 'Chills/Goosebumps' (chills) (1 not at all to 5 clearly). Finally, participants provided demographic information. For details, see the Supplement.

\section{Results}

To test whether being moved has distinctive appraisals and sensations, closeness, morality, weeping, warm chest and chills were regressed on country, being moved (average of moved and touched), sadness, happiness, anxiety, their interactions with country, and video in five separate mixed models. Perceiving increased closeness and morality were both uniquely predicted by being moved and video. Weeping was significantly predicted by being moved, to a lower degree by sadness, and by video. Experiencing a warm chest was best predicted by being moved, to a lower degree also by happiness and country (Norway>US). Finally, chills was predicted by being moved, anxiety, video and country (Norway>US). Table 2 lists the corresponding estimates, their interactions with country and the estimates for video. The Supplement reports the reliability of the moved index, the successful manipulation check, and all test statistics. 


\section{Discussion}

Supporting hypotheses, participants felt more moved and reported more chills/goosebumps and chest warmth in episodes of positive tears than in episodes of negative tears. Appraisals of increased closeness and moral acts mediated the difference between the conditions in the being moved index, suggesting that situations evoking being moved often involve an increase in interpersonal closeness and acts judged as moral.

These results suggest that the main triggers of being moved are interpersonal closeness and morality. A theoretical framework that spans both themes is relational models theory (Fiske, 1992), claiming that four relational models structure our social life. One of them, communal sharing, is experienced as interpersonal closeness. Concurrently, each model is a different foundation of morality (Rai \& Fiske, 2011). Communal sharing could therefore link the two themes, to the extent that the morality appraised was found to be specific to that model. Accordingly, newly formulated kama muta theory posits that a sudden intensification in communal sharing elicits an emotion often labeled being moved (Fiske et al., 2017).

For the positive episodes, we also coded the descriptions regarding whether the participant herself was involved or just observed or heard about the event. A majority of the events $(74 \%)$ were coded as involving the person herself. The two perspectives did not differ in the level of being moved reported, nor did they moderate the pattern of appraisals. This confirms that being moved is the same emotion with the same appraisals both when actively involved and when observing an event.

The frequent reports of being moved experiences when actively involved challenges the characterizations of being moved by Hanich and colleagues (2014), Tan (2009), and Tokaji (2004), who argue that the emotion is not related to agency, and assume it is generally 
experienced only passively by witnessing or observing an event. The present observations also challenge Haidt's (2003) implicit equation of being moved with elevation, where elevation is defined as an experience caused by witnessing others perform acts of moral virtue.

Finally, we tested whether the focal appraisals were better predicted by the other emotions assessed, such as awe and admiration. If that were the case, it would suggest that being moved is a term mainly used in conjunction with another of the emotion terms. However, in Study 1 we found that the being moved index was the strongest predictor of increased closeness, and predicted morality alongside admiration. This suggests that among the terms tested, moved and touched are the primary emotion terms Americans use for weeping because of increased closeness or moral acts. The finding for admiration is at odds with the models of Onu, Kessler, and Smith (2016) and Algoe and Haidt (2009), where moral behavior is seen as eliciting elevation, not admiration.

Inducing being moved, happiness, sadness and anxiety through videos, Study 2 investigated the same question in Norway and the US: Again, perceiving actions as morally right and people as coming closer together were uniquely predicted by being moved, and not by happiness, sadness or anxiety. In addition, although different affective states were related to different sensations, being moved was the only emotion predicting all three: weeping, chills, and a warm feeling in the chest. This was especially the case for the Norwegian sample.

Some accounts propose that crying when being moved is similar to sadness-related crying because, for example, both are triggered by helplessness or powerlessness (Miceli \& Castelfranchi, 2003; Vingerhoets \& Bylsma, 2015). Efran and Spangler (1979) as well as Tokaji (2003) see the release of tension as the primary cause of the tears of being moved. These models would suggest that there is no pattern of appraisals or sensations specific to being moved. Yet we 
found in both studies specificity in appraisals and sensations, relative to the comparison emotions. These data support the view that being moved is a distinct emotion.

In sum, our studies present the first empirical evidence for the appraisals of being moved, as well as characterizing its phenomenology, albeit only subjectively. This paves the way for further inquiry into the nature and consequences of this emotion. As an emotional response to interpersonal closeness and moral acts, this emotion may play a key role in preventing conflict and bringing people together. 


\section{References}

Algoe, S. B., \& Haidt, J. (2009). Witnessing excellence in action: the "other-praising" emotions of elevation, gratitude, and admiration. The Journal of Positive Psychology, 4(2), 105-127. https://doi.org/10.1080/17439760802650519

Benedek, M., \& Kaernbach, C. (2011). Physiological correlates and emotional specificity of human piloerection. Biological Psychology, 86(3), 320-329. https://doi.org/10.1016/j.biopsycho.2010.12.012

Claparède, E. (1930). L'émotion «pure». Extrait Des Archives de Psychologie, 22, 333-347.

Cova, F., \& Deonna, J. A. (2014). Being moved. Philosophical Studies, 169(3), 447-466. https://doi.org/10.1007/s11098-013-0192-9

Darwin, C. (1890). The expression of the emotions in man and animals. Lond: John Murray.

Efran, J. S., \& Spangler, T. J. (1979). Why grown-ups cry. Motivation and Emotion, 3(1), 63-72. https://doi.org/10.1007/BF00994161

Fiske, A. P. (1992). The four elementary forms of sociality: Framework for a unified theory of social relations. Psychological Review, 99(4), 689-723.

Fiske, A. P., Schubert, T. W., \& Seibt, B. (2016). "Kama muta" or "being moved by love": A bootstrapping approach to the ontology and epistemology of an emotion. In J. Cassaniti \& U. Menon (Eds.), Universalism without uniformity: Explorations in mind and culture. Chicago: University of Chicago Press.

Frijda, N. H. (1988). The laws of emotion. The American Psychologist, 43(5), 349-358.

Haidt, J. (2003). The moral emotions. In R. J. Davidson, K. R. Scherer, \& H. H. Goldsmith (Eds.), Handbook of affective sciences (pp. 852-870). Oxford: Oxford University Press.

Hanich, J., Wagner, V., Shah, M., Jacobsen, T., \& Menninghaus, W. (2014). Why we like to 
watch sad films. The pleasure of being moved in aesthetic experiences. Psychology of Aesthetics, Creativity, and the Arts, 8(2), 130-143. https://doi.org/10.1037/a0035690

Hofstede, G. (2001). Culture's consequences: Comparing values, behaviors, institutions and organizations across nations. Thousand Oaks CA: Sage.

House, R., Hanges, P., Javidan, M., \& Dorfman, P. (2004). Culture, leadership, and organizations: The GLOBE study of 62 societies. Thousand Oaks, CA: Sage.

James, W. (1890). The principles of psychology, 2nd vol. Cambridge, MA: Harvard University Press.

Konečni, V. J. (2005). The aesthetic trinity: Awe, being moved, thrills. Bulletin of Psychology and the Arts, 5, 27-44.

Menninghaus, W., Wagner, V., Hanich, J., \& Wassiliwizky, E. (2015). Towards a psychological construct of being moved. PLOS One, 10(6), 1-33. https://doi.org/10.1371/journal.pone.0128451

Miceli, M., \& Castelfranchi, C. (2003). Crying: discussing its basic reasons and uses. New Ideas in Psychology, 21(3), 247-273. https://doi.org/10.1016/j.newideapsych.2003.09.001

Montoya, A. K., \& Hayes, A. F. (n.d.). Two condition within-participant statistical mediation analysis: A path-analytic framework. Psychological Methods.

Neale, S. (1986). Melodrama and tears. Screen, 27, 6-23. https://doi.org/10.1093/screen/27.6.6

Onu, D., Kessler, T., \& Smith, J. R. (2016). Admiration: A Conceptual Review. Emotion Review, 8(3), 218-230. https://doi.org/10.1177/1754073915610438

Panksepp, J. (1995). The emotional sources of "chills" induced by music. Music Perception, 13, $171-207$.

Putterman, L., \& Weil, D. N. (2010). Post-1500 population flows and the long-run determinants 
of economic growth and inequality. The Quarterly Journal of Economics, 125(4), 16271682. https://doi.org/10.1162/qjec.2010.125.4.1627

Rai, T. S., \& Fiske, A. P. (2011). Moral psychology is relationship regulation: moral motives for unity, hierarchy, equality, and proportionality. Psychological Review, 118(1), 57-75. https://doi.org/10.1037/a0021867

Rychlowska, M., Miyamoto, Y., Matsumoto, D., Hess, U., Gilboa-Schechtman, E., Kamble, S., ... Niedenthal, P. M. (2015). Heterogeneity of long-history migration explains cultural differences in reports of emotional expressivity and the functions of smiles. Proceedings of the National Academy of Sciences of the United States of America, 112(19), E2429-36. https://doi.org/10.1073/pnas.1413661112

Scherer, K. R., \& Zentner, M. R. (2001). Emotional effects of music: Production rules. In P. N. Juslin \& J. A. Sloboda (Eds.), Music and emotion: Theory and research (pp. 361-392). Oxford: Oxford University Press.

Schnall, S., Roper, J., \& Fessler, D. M. T. (2010). Elevation leads to altruistic behavior. Psychological Science, 21(3), 315-20. https://doi.org/10.1177/0956797609359882

Tan, E. S. (2009). Being moved. In D. Sander \& K. R. Scherer (Eds.), Companion to Emotion and the Affective Sciences (p. 74). Oxford: Oxford University Press.

Tan, E. S., \& Frijda, N. H. (1999). Sentiment in film viewing. In C. Plantinga \& G. M. Smith (Eds.), Passionate views. Film, cognition, and emotion (pp. 48-64). Baltimore: Johns Hopkins University Press.

Tokaji, A. (2003). Research for determinant factors and features of emotional responses to "kandoh" (the state of being emotionally moved). Japanese Psychological Research, 45, 235-249. https://doi.org/doi:10.1111/1468-5884.00226 
Vingerhoets, A. J. J. M. (2013). Why only humans weep. Unraveling the mysteries of tears. Oxford: Oxford University Press.

Vingerhoets, A. J. J. M., \& Bylsma, L. M. (2015). The riddle of human emotional crying: A challenge for emotion researchers. Emotion Review. https://doi.org/10.1177/1754073915586226

Wassiliwizky, E., Wagner, V., \& Jacobsen, T. (2015). Art-elicited chills indicate states of being moved. Psychology of Aesthetics, Creativity, and the Arts, 9(4), 405-416. 


\section{Tables}

Table 1

Means and Standard Deviations (in Parentheses) for Being Moved Index, Sensations and Appraisals for Positive and Negative Tear episodes. For Each Row, the Simple Effect of Condition is given as the Confidence Interval of the Mean Difference and the Partial Eta Square

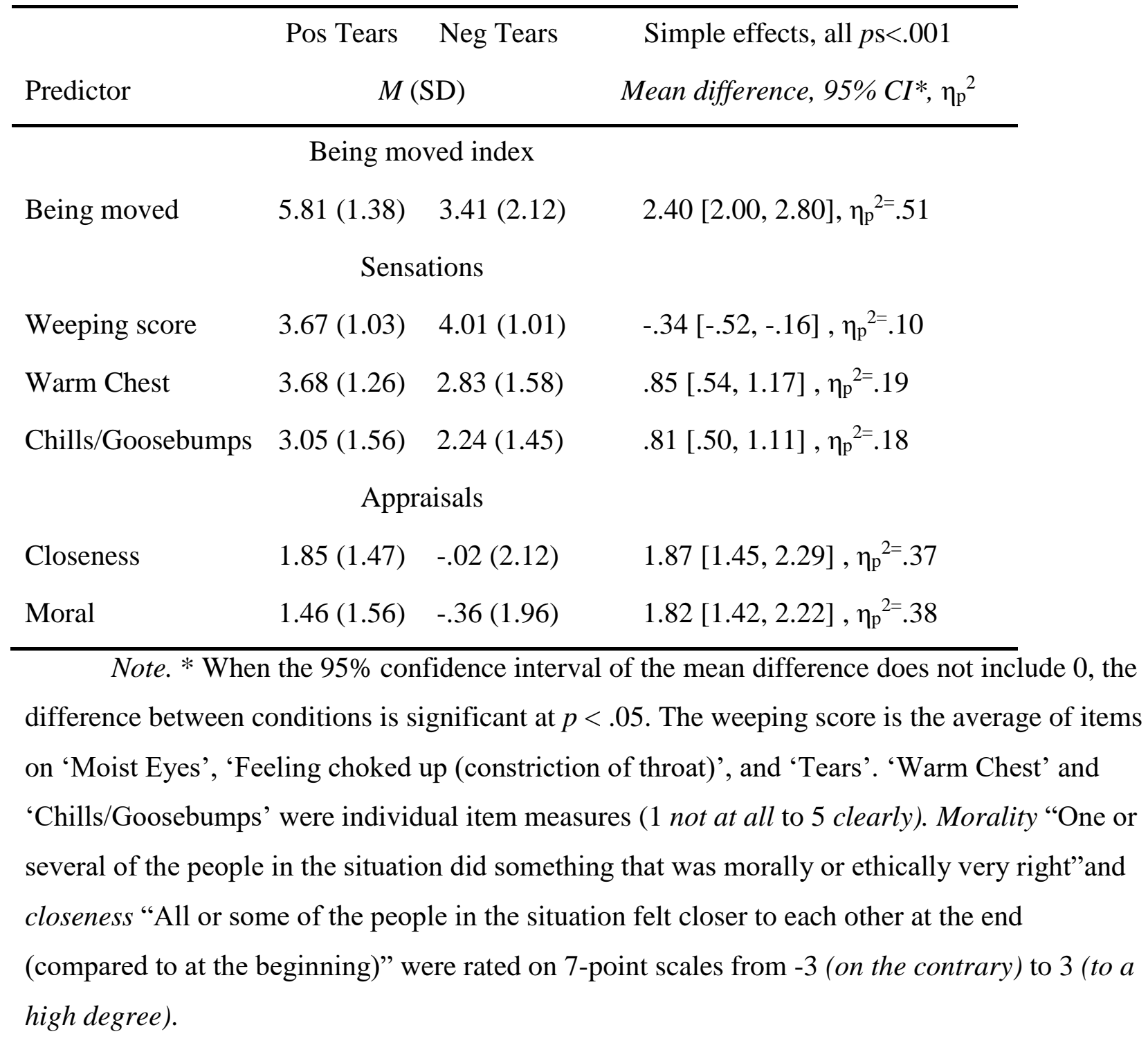


Table 2

Study 2: Prediction of Closeness, Morality and Sensations by Moved or Touched, Happiness, Sadness, and Anxiety for American and Norwegian Participants Separately and Combined. All criteria were measured on scales from 1 to 5

\begin{tabular}{|c|c|c|c|c|c|c|c|}
\hline \multirow[b]{2}{*}{ Predictor } & \multicolumn{4}{|c|}{ All } & U.S. & Norway & \multirow{2}{*}{$\begin{array}{l}\text { Video } \\
\text { estimat }\end{array}$} \\
\hline & $B[95 \% \mathrm{CI}]$ & $\mathrm{df}$ & $t$ & $p$ & \multicolumn{2}{|c|}{$B[95 \% \mathrm{CI}]$} & \\
\hline \multicolumn{8}{|c|}{ Closeness (Model 1) } \\
\hline Moved & $.24[.18, .29]$ & 738 & 7.99 & $<.001$ & $.24[.17, .32]$ & $.22[.13, .31]$ & 3.85 \\
\hline Sad & $.004[-.05, .05]$ & 730 & .14 & .892 & $.01[-.06, .08]$ & $-.004[-.08, .07]$ & $3.59 *$ \\
\hline Happy & $.04[-.01, .09]$ & 738 & 1.43 & .155 & $.05[-.02, .13]$ & $.02[-.06, .10]$ & $1.96^{*}$ \\
\hline Anxious & $.005[-.04, .05]$ & 721 & .21 & .836 & $.03[-.03, .09]$ & $-.02[-.09, .05]$ & $1.86^{*}$ \\
\hline \multicolumn{8}{|c|}{ Morality (Model 2) } \\
\hline Moved & $.21[.15, .27]$ & 738 & 7.16 & $<.001$ & $.24[.16, .31]$ & $.16[.08, .24]$ & 4.32 \\
\hline Sad & $-.002[-.05, .05]$ & 726 & -.06 & .953 & $-.04[-.11, .03]$ & $.05[-.02, .12]$ & $3.81 *$ \\
\hline Happy ${ }^{x}$ & $.01[-.04, .06]$ & 737 & .39 & .698 & $-.01[-.09, .06]$ & $.03[-.05, .10]$ & $2.41 *$ \\
\hline Anxious & $.02[-.02, .07]$ & 726 & 1.04 & .299 & $.04[-.02, .10]$ & $-.01[-.07, .06]$ & $1.79 *$ \\
\hline \multicolumn{8}{|c|}{ Weeping (Model 3) } \\
\hline Moved $^{\mathrm{x}}$ & $.35[.29, .41]$ & 739 & 11.07 & $<.001$ & $.28[.21, .36]$ & $.43[.33, .53]$ & 2.41 \\
\hline Sad & $.07[.02, .13]$ & 723 & 2.56 & .011 & $.11[.04, .19]$ & $.03[-.06, .11]$ & $1.82 *$ \\
\hline Happy & $-.02[-.08, .04]$ & 737 & -.68 & .498 & $-.01[-.08, .07]$ & $-.02[-.11, .07]$ & $1.72 *$ \\
\hline Anxious & $.04[-.01, .09]$ & 732 & 1.52 & .129 & $.08[.01, .14]$ & $-.003[-.08, .07]$ & $1.68^{*}$ \\
\hline \multicolumn{8}{|c|}{ Chills (Model 4) } \\
\hline Moved $^{\mathrm{x}}$ & $.22[.15, .30]$ & 726 & 5.72 & $<.001$ & $.07[-.02, .15]$ & $.39[.25, .52]$ & 2.18 \\
\hline Sad & $.01[-.06, .08]$ & 703 & .27 & .785 & $.06[-.02, .15]$ & $-.04[-.15, .06]$ & $2.35^{*}$ \\
\hline Happy & $.04[-.03, .11]$ & 722 & 1.03 & .305 & $.11[.02, .20]$ & $-.07[-.18, .05]$ & 2.21 \\
\hline Anxious $^{x}$ & $.21[.15, .27]$ & 736 & 6.91 & $<.001$ & $.28[.20, .35]$ & $.16[.07, .26]$ & 2.18 \\
\hline \multicolumn{8}{|c|}{ Warm Chest (Model 5) } \\
\hline Moved $^{\mathrm{x}}$ & $.38[.31, .44]$ & 726 & 11.51 & $<.001$ & $.29[.22, .37]$ & $.45[.35, .56]$ & 2.29 \\
\hline Sad & $.03[-.03, .08]$ & 704 & .88 & .378 & $.06[-.01, .14]$ & $-.01[-.10, .07]$ & 1.67 \\
\hline Happy & $.14[.08, .20]$ & 723 & 4.50 & $<.001$ & $.17[.09, .24]$ & $.10[.01, .19]$ & 2.00 \\
\hline Anxious & $.05[-.003, .10]$ & 736 & 1.85 & .065 & $.07[.01, .14]$ & $.02[-.06, .10]$ & 2.65 \\
\hline
\end{tabular}

Note. ${ }^{\mathrm{x}}$ indicates a significant $(p<.05)$ interaction of this predictor with country of residence. Separate mixed models were computed for the two samples combined and separately. Test statistics are reported only for the combined sample. Video intercepts indicate the value of the criterion for each of the four videos at the average of all other predictors, which were centered. Note that the row header in this case does not refer to the emotion measured but to the content of the video shown. Intercepts with an asterisk differ significantly from that of the moving video. This is additional evidence for the appraisals' role in being moved. 


\section{Supplement "Interpersonal closeness and morality predict feelings of being moved" \\ Study 1}

\section{Method}

Participants. The study was advertised as a 'Survey on Relations and Emotions'. In total 134 US American participants were sampled on Amazon MTurk, requesting only workers with at least $95 \%$ approval rate. Participants who failed to provide both episodes were excluded. We normally aim for at least 150 participants when some of our research questions regard correlations (cf. Schönbrodt \& Perugini, 2013). However, due to the design of Amazon MTurk, we cannot close a study to precisely hit that mark.

Measures. Emotions were assessed with items on moved, touched, happy, sad, angry, anxious, admiration, pride, awe. We also included two non-emotion terms, 'uplifted', and 'unity' for exploratory reasons. We did not predict discriminant validity from these terms. Nevertheless, when including them in the multi-level analysis, being moved remains a significant predictor of closeness and morality. In addition, unity also significantly predicts closeness, $B=.23[.11, .36]$, $t(250)=3.57, p<.001$.

Next, the focal appraisals of morality "One or several of the people in the situation did something that was morally or ethically very right" and closeness "All or some of the people in the situation felt closer to each other at the end (compared to at the beginning)" were assessed along with three exploratory items: "Somebody who was excluded at first was included at the end" (inclusion), "All or some of the people in the situation overcame big obstacles during the events" (obstacles), and "All or some of the people in the situation became somehow more human during the events" (human). All were rated on 7-point scales from -3 (on the contrary) to 3 (to a high degree), with a midpoint of 0 (not at all). 
Sensations were assessed with items on 'Moist Eyes', 'Warm Chest', 'Chills/Goosebumps', 'Feeling choked up (constriction of throat)', and 'Tears', rated on scales from 1 (not at all) to 5 (clearly). Furthermore, we also included exploratory items on 'I smiled', 'I sighed or made a sound like 'Ahh', 'I put my hand to my chest or face'.

Prior to the demographic questions, participants filled in the revised Adult Attachment Scale (AAS, Collins, 1996) and the Interpersonal Reactivity Index (IRI, Davis, 1983).

\section{Results}

Manipulation check. To check that the episodes were of opposing valence, we conducted a 2 (emotion: happy vs. sad) x 2 (condition: positive vs. negative) repeated-measures ANOVA. Results showed a significant main effect of condition, $F(1,131)=14.80, p<.001$, $\eta_{\mathrm{p}}{ }^{2}=.10$, with higher ratings for positive episodes, and the expected interaction effect, $F(1,131)=544.97, p<.001, \eta_{\mathrm{p}}{ }^{2=} .81$. Ratings of happiness were higher for the episodes involving positive tears while ratings for sadness were higher for the episodes involving negative tears (Table S1). To check for self-reported weeping, ratings on moist eyes, tears and feeling choked up were averaged into a weeping score. Both positive tears, and negative tears evoked weeping different from 1 (not at all), ts $(131)>30, p s<.001$.

Being moved index. An unconditional three-level hierarchical model was estimated in HLM with being moved and touched as measurements at the first level, condition at the second level, and participant at the third level (Nezlek, 2011). Reliability at the first level was .88; therefore, the two measures were averaged.

Appraisals. In addition to the analysis in the main article, we also compared ratings on all five appraisals, closeness, morality, inclusion, humanness and obstacles between conditions in a 5x2 repeated ANOVA. In line with hypothesis 3, all ratings were higher for positive than 
negative tears episodes, $F(1,129)=90.48, p<.001, \eta_{\mathrm{p}}{ }^{2}=.41$. Their mean levels also differed, $F(4,480)=26.38, p<.001, \eta_{\mathrm{p}}{ }^{2}=.17$, with closeness having the highest ratings. The mean difference between conditions was highest for closeness and morality, resulting in an interaction effect, $F(4,492)=6.12, p<.001, \eta_{\mathrm{p}}{ }^{2}=.05($ Table S2).

For exploratory reasons, we also checked how being moved correlates with each of the appraisals for positive tears, and how they correlate with each other (Table S3).

Appraisals and Being Moved. Because of the repeated nature of our design, we used MEMORE (Montoya \& Hayes, 2015) with 10000 bootstrap samples to test our mediation model.

Perspectives. We examined whether participants recalled episodes from different perspectives. Therefore, two assistants coded episodes of positive tears independently. Firstperson experiences were defined as originating within the person, second-person as originating from actions of a relationship partner, and third-person as originating from witnessing interactions between others. First and 2nd person experiences were combined into one code because these experiences often occur simultaneously and are hard to distinguish. Both assistants coded the majority of the cases as $1^{\text {st }} / 2^{\text {nd }}$ person. The two codings agreed moderately $(\kappa=.55$ $[.41 ; .69], p<.001)$. Disagreement was resolved through discussion. In the final coding, $73.5 \%$ (97) were coded as 1st/2nd person (participating), and 26.5\% (35) as 3rd person (witnessing).

Other emotions, being moved, and appraisals. In the two mixed models reported in the article (Table S4), intercepts for participants varied randomly, however, they did not differ significantly (Wald $Z<1.84$ ). We also repeated both analyses with condition as a main effect. In neither analysis did condition have an effect $(F \mathrm{~s}<1.9, p \mathrm{~s}>.17)$. We therefore did not include that factor. 


\section{Study 2}

\section{Method}

Participants. The study was advertised as a survey entailing 'Watching videos; reporting emotions'. US participants were sampled on Amazon MTurk requesting only workers with at least $95 \%$ approval rate, while Norwegian participants completed the study as part of a mandatory course requirement. In total 250 participants were sampled, resulting in 996 different video viewing. Participants who reported technical problems were excluded, as were Norwegian students indicating that they only wanted to participate for educational purposes, an option we always give them when they participate for course credit. Data for participants for individual videos were also excluded when they had not watched the video entirely, which was tracked with a timer. The final sample thus consisted of 220 participants (139 women, 75 men, 6 unknown gender, 108 Norwegians, 112 US Americans) contributing 758 video impressions. All US American participants completed the English version and all Norwegian participants the respective Norwegian version of the questionnaire, therefore language is redundant with country.

Materials. For the moving video 'Thai Medicine' was chosen as it had the highest ratings in earlier studies. As the sad video, we edited a video about 'Two Orphans' and presented the particularly sad middle part of that video. For the cheerful video, we chose a short scene from the movie 'Singin' in the Rain', depicting Gene Kelly happily dancing and singing in the rain. Finally, a scary video scene was taken from 'The Shining,' featuring a young boy meeting ghosttwins in a hotel hallway this video has been utilized in earlier research to evoke fear (Gross \& Levenson, 1995).

After providing informed consent and before watching the videos participants completed an 8-item version of the UCLA loneliness scale (Hays \& DiMatteo, 1987) assessing general 
disposition of loneliness. The scale includes items such as 'I lack companionship" or 'People are around me but not with me"' (1 never to 4 often).

The Norwegian terms for the emotions were rørt/beveget (moved/touched), glad (happy), trist (sad) and engstelig (anxious). For the sensations, the terms were tårer/våt $i$ фyekroken (Tears/Moist eyes), frysninger/gåsehud (Chills/Goosebumps), and varme i brysten (Warm chest). The five appraisal items were en eller flere av karakterene gjorde noe som var veldig moralsk eller etisk riktig (morality), alle eller noen av karakterene i filmen følte seg narmere hverandre til slutt (sammenlignet med i starten) (closeness), noen som var utelatt i begynnelsen ble inkludert til slutt (inclusion), alle eller noen av karakterene overvant store hindringer i lфpet av historien vist $i$ videoen (obstacles), and alle eller noen av karakterene på en eller annen måte ble mer menneskelige i lфpet av hendelsene som fant sted $i$ videoen (humanness).

After watching each video, participants not only completed the items on emotions, sensations and appraisals but also two items assessing to what extent they identified with the characters in the video and whether they thought love and affection were expressed during the short clips.

After all videos, participants completed the Interpersonal Reactivity Index (IRI, Davis, 1983) measuring empathy on different subscales including empathic concern, perspective taking, personal distress and fantasy. Finally, participants were asked whether they had seen the video before, experienced technical difficulties, or watched the video with sound, before providing basic demographic information. 


\section{Results}

Being Moved Index. As in Study 1, reliability of moved and touched was estimated in HLM indicating high reliability for both U.S. (.96) and Norwegian sample (.89). The two were therefore averaged into the being-moved index.

Manipulation check. Emotion (being moved index vs. happy vs. sad vs. anxious) and video were used as within-subject factors and country and gender as between-subject factors in a $4 \times 4 \times 2 \times 2$ mixed ANOVA. Note that this analysis is based on a sample of 130 participants with complete datasets. Results showed a significant interaction effect for the two within factors, $F(6,767)=183.56, p<.001, \eta_{\mathrm{p}}^{2}=.59$, with the emotion ratings differing across videos. Comparisons revealed successful induction of the four respective emotions. Specifically, fear ratings were highest for the scary video, the being moved index highest for the moving video, and sadness was highest in the sad video. Ratings for happiness were highest for the cheerful video but did not differ significantly from the moving video (Table S5).

We also observed a two-way interaction for type of video and gender, $F(3,350)=4.31, p$ $=.006, \eta_{\mathrm{p}}{ }^{2}=.03$, with women indicating generally higher ratings for the sad video. In addition, gender interacted with emotion ratings and video in a three-way interaction, $F(6,767)=3.59, p$ $=.002, \eta_{\mathrm{p}}^{2}=.03$. Women rated the moving video as more moving and the sad video as sadder than men. No other effects were significant.

Predicting morality, closeness and sensations. In the five mixed models reported in the article, intercepts for participants varied randomly. Table S6 lists the test statistics for the effects not reported in the article: the fixed effects of country and video as well as the random effect of participant. 
Additional appraisals across the affective states. Appraising inclusion of someone who was excluded at first was predicted by feeling moved, $B=.14[.06, .21], t(721)=3.63, p<.001$ and also to a lesser degree by happiness, $B=.08[.01, .15], t(716)=2.34, p=.019$. Perceiving the characters overcoming big obstacles was again uniquely predicted by being moved, $B=.22$ $[.15, .29], t(739)=6.28, p<.001$. Finally, perceiving someone as becoming more human was predicted by being moved, $B=.23[.16, .30], t(719)=6.22, p<.001$, and to a lesser degree by happiness, $B=.09[.03, .16], t(715)=2.70, p=.007$ (Table S7). 


\section{References}

Collins, N. L. (1996). Working models of attachment: Implications for explanation, emotion, and behavior. Journal of Personality and Social Psychology, 71(4), 810-832. http://doi.org/10.1037/0022-3514.71.4.810

Davis, M. H. (1983). Measuring individual differences in empathy: Evidence for a multidimensional approach. Journal of Personality and Social Psychology, 44(1), 113126. http://doi.org/10.1037/0022-3514.44.1.113

Gross, J. J., \& Levenson, R. W. (1995). Emotion elicitation using films. Cognition \& Emotion, $9(1), 87-108$.

Hays, R. D., \& DiMatteo, M. R. (1987). A short-form measure of loneliness. Journal of Personality Assessment, 51(1), 69-81.

Montoya, A. K., \& Hayes, A. F. (2015). Two condition within-participant statistical mediation analysis: A path-analytic framework. Manuscript Submitted for Publication.

Nezlek, J. B. (2011). Multilevel modeling for social and personality psychology. Thousand Oaks, CA: Sage.

Schönbrodt, F. D., \& Perugini, M. (2013). At what sample size do correlations stabilize?. Journal of Research in Personality, 47(5), 609-612. 


\section{Supplementary Tables}

\section{Table S1}

Study 1: Means and Standard Deviations (in Parentheses) for Manipulation Check. For Each Row, the Simple Effect of Condition is given as the Confidence Interval of the Mean Difference and the Partial Eta Square

\begin{tabular}{llll}
\hline & Pos Tears & Neg Tears & Simple effects, all $p \mathrm{~s}<.001$ \\
Predictor & $M(\mathrm{SD})$ & & Mean difference, $95 \% \mathrm{CI}^{*}, \eta_{\mathrm{p}}{ }^{2}$ \\
\hline Happiness & $6.03(1.33)$ & $1.73(1.55)$ & $4.30[3.94,4.67], \eta_{\mathrm{p}}{ }^{2}=.81$ \\
Sadness & $2.28(1.71)$ & $5.93(1.50)$ & $3.65[3.27,4.04], \eta_{\mathrm{p}}{ }^{2}=.73$
\end{tabular}

\section{Table S2}

Study 1: Zero-order correlations among the being moved index and the five appraisals for episodes asking for positive tears.

\begin{tabular}{lllllll}
\hline Variables & 1 & 2 & 3 & 4 & 5 & 6 \\
\hline 1. Being Moved & - & & & & & \\
2. Morality & $.191^{*}$ & - & & & & \\
3. Closeness & $.468^{* *}$ & $.558^{* *}$ & - & & & \\
4. Inclusion & .157 & $.364^{* *}$ & $.463^{* *}$ & - & & \\
5. Obstacles & .160 & $.321^{* *}$ & $.368^{* *}$ & $.343^{* *}$ & - & \\
6. Humanness & $.368^{* *}$ & $.523^{* *}$ & $.575^{* *}$ & $.480^{* *}$ & $.486^{* *}$ & -
\end{tabular}

Note. $* p<.05, * * p<.001$ 


\section{Table S3}

Means and Standard Deviations (in Parentheses) for Appraisals for Positive and Negative Tear episodes. For Each Row, the Simple Effect of Condition is given as the Confidence Interval of the Mean Difference and the Partial Eta Square

\begin{tabular}{lccc}
\hline & Pos Tears & Neg Tears & \multicolumn{1}{c}{ Simple effects, all $p s<.001$} \\
Predictor & $M(\mathrm{SD})$ & Mean difference, 95\% $C I^{*}, \eta_{\mathrm{p}}{ }^{2}$ \\
\hline Closeness & $1.84(1.47)$ &. $.04(2.12)$ & $1.88[1.45,2.30], \eta_{\mathrm{p}}{ }^{2=} .38$ \\
Moral & $1.45(1.56)$ &. $.38(1.95)$ & $1.82[1.42,2.23], \eta_{\mathrm{p}}{ }^{2=} .37$ \\
Human & $1.21(1.60)$ &. $.01(1.98)$ & $1.22[.82,1.61], \eta_{\mathrm{p}}{ }^{2=} .22$ \\
Obstacles & $.97(1.71)$ &. $.25(1.93)$ & $1.22[.84,1.61], \eta_{\mathrm{p}}{ }^{2=} .23$ \\
Inclusion & $.37(1.78)$ &. $.79(1.72)$ & $1.16[.79,1.53], \eta_{\mathrm{p}}{ }^{2=.23}$ \\
\hline
\end{tabular}

Note. * When the $95 \%$ confidence interval of the mean difference does not include 0 , the difference between conditions is significant at $p<.05$. 


\section{Table S4}

Study 1: Prediction of Closeness and Morality by Predictors of Being Moved, Happiness,

Sadness, Anger, Anxiousness, Admiration, Awe, and Pride.

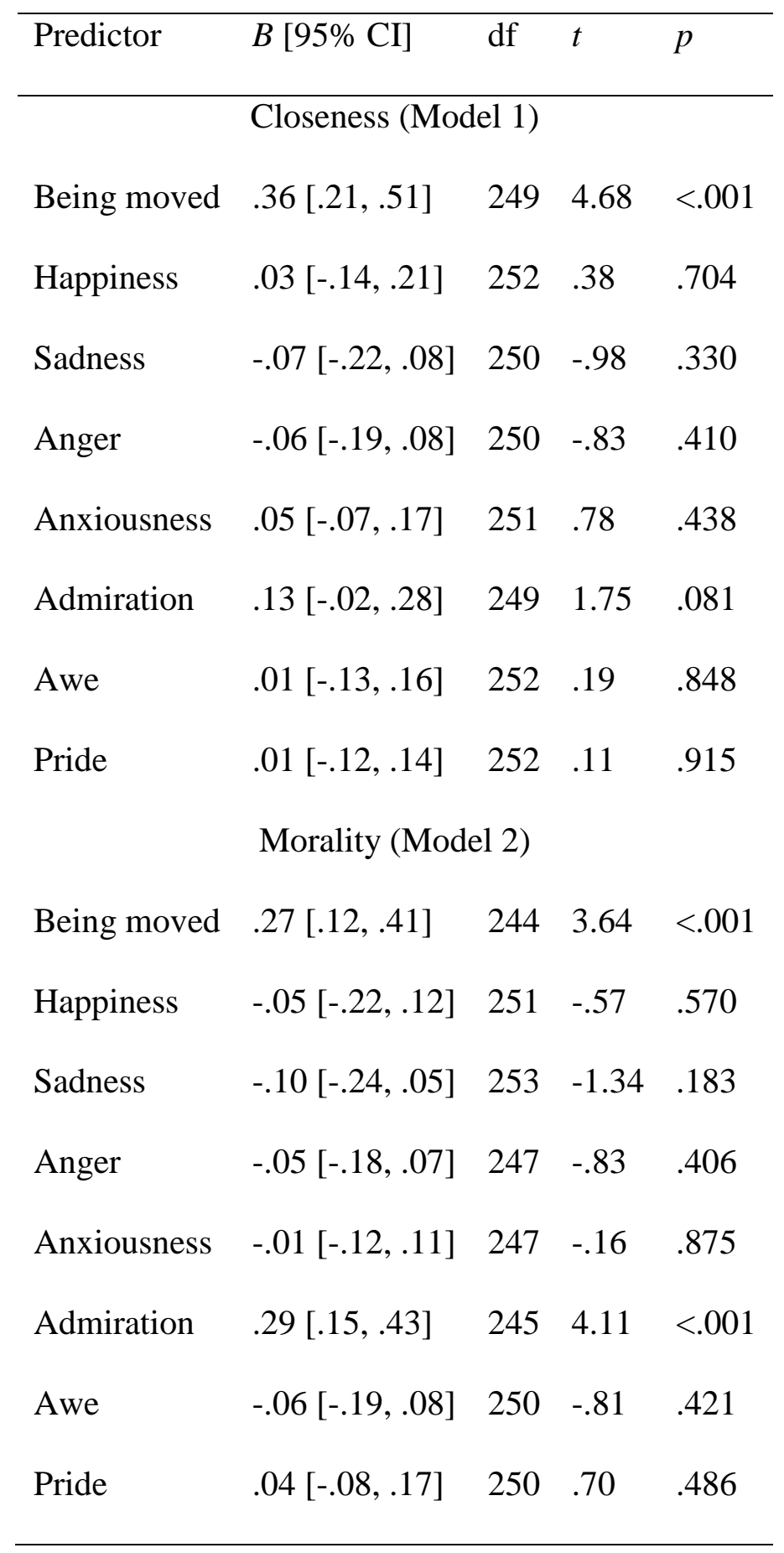




\section{Table S5}

Study 2: Estimated Means and Standard Errors of the Being Moved Index, Sadness, Happiness, and Anxiousness for the Four Different Videos.

\begin{tabular}{lcccc} 
& \multicolumn{4}{c}{ Video } \\
& Moving & Sad & Cheerful & Scary \\
\cline { 2 - 5 } Emotion reported & & \multicolumn{3}{c}{$M(S E)$} \\
\hline Being moved & $5.96(.12)$ & $4.35(.17)$ & $2.69(.16)$ & $1.70(.10)$ \\
Sadness & $3.67(.18)$ & $4.39(.18)$ & $1.17(.04)$ & $2.04(.14)$ \\
Happiness & $5.24(.15)$ & $2.28(.15)$ & $5.22(.14)$ & $1.38(.09)$ \\
Anxiousness & $1.91(.19)$ & $2.62(.17)$ & $1.41(.09)$ & $3.91(.19)$ \\
\hline
\end{tabular}




\section{Table S6}

Study 2: Fixed effects of video and country ( $F$ test) and random effect of participant (Wald Z test) for the five mixed models, as well as for the three additional appraisals.

\begin{tabular}{lllllll}
\hline Criterion & Video & $p$ & Country & $p$ & Participant & $p$ \\
\hline Closeness & $F(3,676)=100.13$ & $<.001$ & $F<1$ & & Wald $Z=2.21$ & .027 \\
Morality & $F(3,670)=124.99$ & $<.001$ & $F(1,203)=2.35$ & .127 & Wald $Z=2.60$ & .009 \\
& & & & & & \\
\hline Weeping & $F(3,668)=12.69$ & $<.001$ & $F<1$ & Wald $Z=3.04$ & .003 \\
Chills & $F(3,651)=20.40$ & $<.001$ & $F(1,202)=6.30$ & .013 & Wald $Z=4.12$ & $<.001$ \\
Warm & $F<1$ & & $F(1,197)=7.14$ & .008 & Wald $Z=3.93$ & $<.001$ \\
Chest & & & & & & \\
\hline Inclusion & $F(3,648)=31.77$ & $<.001$ & $F<1$ & & Wald $Z=4.37$ & $<.001$ \\
Obstacles & $F(3,670)=38.27$ & $<.001$ & $F(1,198)=1.35$ & .246 & Wald $Z=2.47$ & .013 \\
Humanness & $F(3,646)=9.55$ & $<.001$ & $F(1,207)=2.58$ & .109 & Wald $Z=4.88$ & $<.001$ \\
& & & & & & \\
\hline
\end{tabular}




\section{Table S7}

Study 2: Prediction of Additional Appraisals by Predictors of Being Moved, Happiness, Sadness and Anxiety for U.S. American and Norwegian Participants Separately and Combined.

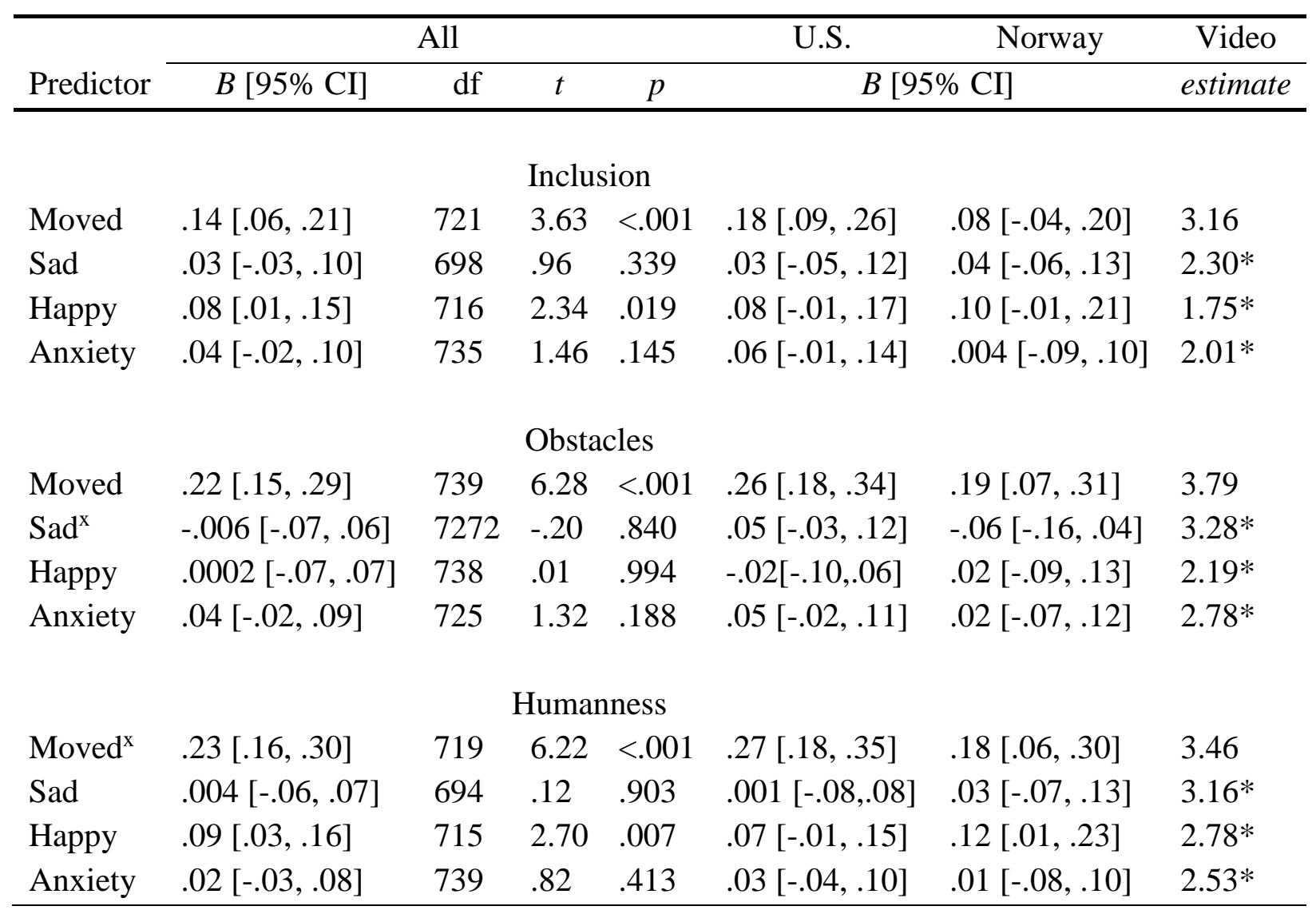

Note. ${ }^{\mathrm{x}}$ indicates a significant interaction of this predictor with nationality $(p<.05)$. Video intercepts indicate the value of the criterion for each of the four videos at the average of all other predictors, which were centered. Note that the row header in this case does not refer to the emotion measured but to the content of the video shown. Intercepts with an asterisk differ significantly from that of the moving video. 


\section{Examples for episodes recalled by participants (Typos corrected)}

To give an impression of the kinds of episodes that participants recounted in each of the conditions, we present below a random selection of 15 episodes per condition, slightly copyedited.

\section{Negative tears}

I had to sell my Cannon because I lost my job and couldn't pay my car note. I only had the camera for three months and felt bad after I sold it. I love art and photography and giving up my camera was like giving up my right hand. I think about it every day and it sometimes makes me sad just thinking about it. I'm now in a better place financially and found a great job. Hopefully I'll be able to buy a camera in the next few months.

Having recently fought with my significant other over our finances caused some hurtful and negative things to be said to one another. While neither of us would ever want to hurt one another, sometimes the situations we are faced with cause us to experience lots of stress and anger. As the holidays approach and the bills continue to pile up, we often discuss our finances and the troubles we are having. These fights escalate and both of us say things that make the other feel worse about themselves. Last time my girlfriend said she was sick of me and I was useless, while she didn't mean this, it made me tear up regardless and question my worth.

I was disappointed in myself for the way my life is going. I had told myself time and time again that I would stop doing foolish things. I even made a promise to myself and God that I would quit. I broke my promise and felt really bad about myself. I'm trying to forgive myself for that and stick to the promise I originally made.

My 2 year old son fell down the front door steps and scratched up his face pretty bad. He is pretty stable when walking but was not used to the steps. He didn't realize that there were steps below him and just kept on walking. He fell and busted his to lip, nose, and forehead. The fall caused scratches and he bled. I felt terrible because I should have known better than to let him walk down the steps, but there were only two steps down to the sidewalk and thought he'd just scoot down them. He cried and cried and cried some more when I tried to clean him up and it made me teary eyed and I wanted to cry with him.

My son is depressed. He's having a hard time now. Things are hard for him. He's sad every day. I want to help him but I can't. When I listen to him tell me how he feels and I try to help, I hear him in so much pain that it hurts me deeply. I cry, just as I am crying now thinking of him and his hurt.

I came home from college and saw my dog that I've had since I was a child. He is really old now - almost 14 years, which is definitely getting up there for dogs. He can't control his bowels or 
bladder very well any more, he's mostly blind and he's had a lot of diseases. I was pretty upset when I saw him because I know he's going to die before long, and he's been sort of a life companion ever since I was young.

About a month ago I left my current city and moved out of state. I had to say goodbye to all my friends and family that lived there, in a state where I had lived for over 20 years. It was so sad to know that I wasn't sure the next time that I would see all my friends, or when I would be together with my family again. I knew that the move would be good for me, but I felt bad because I knew my friends and family were upset about it too.

A recent episode I recall where I cried because of a negative feeling is when I got into an argument with my mother and said some things to her that I later regretted. I did not cry during the argument, I cried after the argument after reflecting on what I said and realizing I screwed up. Fortunately, I was able to apologize later and we made up in the end.

I have been having difficulty with my feelings lately surrounding my boyfriend and the amount of sarcasm he uses towards me. I know I ultimately have a very thin skin, but nonetheless I was tired and got a little weepy the other night when he called me petty "as a joke" and told me I have a terrible memory. I felt like I was not being treated with kindness, and when I tried to explain I got frustrated when he provided examples for his reasoning.

When my mother died after a very very short amount of time from her finding out she had cancer I bawled my eyes out. It was horrible. We expected her to make it and have at least another year with us but she became dehydrated from the radiation. We didn't know it would happen. They couldn't reverse it and we lost her. I'd only been home 3 years when she died. I didn't have nearly enough time with her and I lost her, my mom, my best friend, my confidant. I was beside myself.

Once my wife and I got into an argument over my new job and the money we were making. I was okay with the lower salary but she thought I deserved more and blamed me for not searching for a job sooner. I am a procrastinator and some of the things she said really hurt my feelings. We didn't talk for a week after that fight.

My friend's dog died last year. I knew the dog had died and had been very sad for my friend, but I had not actually talked to my friend about how it happened. My friend told me the story of how the dog had contracted Lyme disease and became very ill. After a few weeks the dog was not only physically unwell but was also suffering from mental and behavioral issues. The dog's behavior became very aggressive, and escaped the house and attacked an elderly woman. Animal control was contacted to deal with the dog, and because it was aggressive they put the dog down. My friend's feeling of helplessness and utter sadness broke my heart. 
I have suffered numerous setbacks recently, and my life has become quite challenging, to say the very least. I am normally quite stoic and controlled about such day-to-day misfortunes, but in a moment of weakness lately I succumbed to my burdens and wept for a short time. Oddly, the experience was not cathartic, and while I didn't regret it I felt as if it had been just a transient episode of no real benefit to me, and that it had no meaning or lasting effect. Perhaps I controlled myself too much even then

I didn't cry when my Dad died, we live far apart so I talked to him often but didn't see him much. We were very close, so except for the phone calls, it really didn't seem like he was gone. Maybe 16 months after he passed I was having a particularly frustrating day and I just sat down and cried a little because it hit me that my best friend wasn't around anymore to share my frustrations. I don't think I realized before that moment that he really was gone.

My sister has a friend who was diagnosed with brain cancer. The minute she told me I got moist eyes and starting shedding tears. Sometimes you hear stories like this, but considering this story was so close to home, it really hit me. I started thinking about how she must feel and how I would feel if I were her. It was overwhelming emotion because it makes you think about life and the meaning of it and how unfair it can be sometimes.

\section{Positive tears}

My granddaughter was born very premature, at only one pound and six ounces. She spent five months in the hospital, and was finally released. She had to be readmitted and then was released again. She was very small, and just ensuring her physical health was staying on par was difficult. I retired early in order to care for her. A few months ago she seemed to gain weight and started to bloom. She became more communicative and expressive. After being under much stress to ensure that she ate and was isolated from germs, being able to appreciate her personality finally was wonderful. The baby who was mostly receptive, even more so than full term babies, started to interact with her environment more. I could make her laugh and smile. One day I picked her up to change her and she put her little arms around me, put her head on my shoulder, and then hugged me. She then picked her head up, looked at me and smiled. She is eleven months now, and behind in some of her developmental skills, but can feel and share love. Knowing that she can do this is a wonderful thing, and I will never forget the first time that the baby hugged me tight!

I often recall my late father, who passed away about five years ago. Memories of him come to me unbidden at various times, sometimes triggered by something, sometimes out of nowhere. A recent example is my recollection of him teaching me to drive. I was having trouble learning to operate a manual transmission, and he was both amused and encouraged by my struggles. He had begun driving farm equipment (including tractors and pick-up trucks) at the age of three, so he naturally got a laugh out of his late-tee-aged son still grinding gears and missing shifts. I learned to drive in my early teens, but only automatic transmissions. Yet despite my advanced age, my 
dad was still eager and willing to help me learn something new. Remembering this experience, and remembering my father generally, always brings tears to my eyes.

It was when I was thinking about my marriage and my children growing up. My ex-husband writes and performs music and he had written a song for me that my son had to tell me about. When I first saw and heard the video I was definately moved to tears as he hd put his feelings about our relationship in the words of the song. Not only that, but my daughter-in-law sang the song, which even made my emotions stronger. I still have a great deal of love for my ex-husband who is remarried and happy with his life. He is the father of our children, and we both realized long ago that even though we were not together any more, we still cared about each other. It made me realize how lucky I was to have such a great family.

The last moment I can remember with a tear is watching a video on youtube about colorblind finally seeing color. It made me reflect and think that I take things for granted and some people are so happy with just being able to do things we do not even appreciate or acknowledge as important in our life. The video starts off with a person trying on EnChroma glasses without even knowing it and finally seeing purple for the first time and asking in a vulgar but honest reaction of surprise, "Is this purple?" The person teared up and I could feel his happiness and emotion to actually feel a joy of tear for the person and the many more that will finally get to experience this amazing beautiful world.

I shed a tear because of a positive feeling the first time I saw my son. I would risk my life over and over again to see him. His eyes look like his father's eyes. I love them both so much. I would live my life taking care of my family. My family is my life now. I will forever love them. I thank the Lord for giving me such a wonderful family.

My four year old daughter recently went trick or treating on Halloween. She dressed up as a frozen fairy princess, with a blue glitter tutu, wings and a wand. She was so excited to go on her first trick or treat. She went with my husband and me downtown. She was so excited about her costume, she said thank you, thank you for my beautiful costume. It was so sweet that I teared up with emotion over how happy she was in that moment. We went house to house and she practiced saying trick or treat and she was so cute, she made sure to say thank you after every treat. We had a really great time as a family, it was a lovely positive memory that makes me tear up with happiness when I think about her special day.

2 months, ago, my first nephew was born. The moment I went into the hospital room and saw him, my eyes teared up. This was the first child that any of my siblings had, so I had no idea how it would feel. The feeling was much deeper than I ever thought it could be. While I knew I would be elated, I didn't think it would bring tears to my eyes, but it did. When my family and I were in the waiting room and heard that the baby arrived, we were so happy. But it wasn't until we walked into the room and saw the baby that it became really real and the tears were shed. 
My son is in marching band and when I went to watch their first performance of the season I was overcome with pride. I was so happy to see him proudly participating in something that he loves that I was overcome with emotion and teared up as I watched. I'm sure the music helped a bit too, as I am easily overcome with emotion when music is involved.

On my birthday a few days ago, I got a phone call from my ex-husband to wish me happy birthday. I was thinking about how happy I am to be able to maintain a close friendship/relationship with my ex-husband. That isn't usually the case for most people, so I'm very happy that we have worked through some conflicts and have remained close in spite of not being able to be married anymore.

I think that during my graduation ceremony, I got a little bit teary-eyed. I felt so happy because of my accomplishment, and it made me reflect on all the effort that it took to get there. Also, I felt very sad that my life in College was going to end. I thought of all the people that helped me along to get to that point. All my friends in college, the teachers that helped me and encouraged me, and also my family and friends that were there every step of the way helping me reach my goals. It was a very uplifting experience, and one that I don't think I will ever forget.

It was my university graduation ceremony. It was a very beautiful day. Everyone in my family attended the ceremony. I was very excited and anticipated this day as I was finally able to do something for my parents. They were very excited that I was about to graduate and I was very happy for them. I worked very hard for this day as I studied very hard and I also took on part time jobs to fund my education. My parents also contributed towards my tuition so I was very grateful and happy that they could attend the ceremony. We took some time to walk around the campus before the ceremony and we talked and took pictures along the way. We had a great time talking about old times and what we would like to do in the future. The ceremony went by smoothly and I receive my diploma. The family took one final picture for the evening and we headed home afterwards. It was one of the most important days of my life and I am very glad that I was able to share it with my family. I was so glad that I got teary eyed at the end of the night.

After I finished my first half marathon, I felt emotional at dinner with my husband. We were reflecting on how it went, and I was thinking about how I had bone cancer/total knee replacement as a kid. At the time, I felt like the world was over because I couldn't play soccer anymore. At dinner with my husband, I was just really proud of how far I had come and that I accomplished something I didn't think was possible. I was also feeling so appreciative of all the support he gave me throughout the whole training months and race.

I have some good friends and at one particular time I was in problems and a friend was there to bail me out. I was in some deep hot water at a store where I had broken something because I was just looking and searching through the store but my hand bounced off a [...] they had, so the owner said the [...] cost 150 but I had no money at the time so I had to end up ask my friend for 
the loan as he was there at the store with me, luckily he had 250 on him and he was able to lend me the 150 or else the store keeper said he would call the cops on me to this day from he did me that a very good deed I loved him so much knowing he was there for me and he appreciated me so much to have lend me so much money.

My friends and I wanted to lose some weight before a friend's wedding. We worked out together, ate the same meals by cooking them in advance. We'd take turns on cooking so each one of us only needed to cook once per month. We held each other accountable. It was a great experience because I knew that I had amazing and loving friends. I got moist eyes thinking about the support that I had received from them.

I shed a tear due to a positive thing when my cousin's baby was born. My cousin had such a rough life when she was younger. She had been through it all, so to speak. The baby was so gorgeous and they both needed one another so much. They gave one another the thing that every human wants: unconditional love. 